\title{
Effects of tumor microenviromental factors on VEGF expression
}

\author{
FENG WANG $^{1}$, PING XU ${ }^{1}$, KUANG-CHEN XIE ${ }^{1}$, XIA-FANG CHEN ${ }^{1}$, CHUAN-YUAN LI $^{2}$ and QIAN HUANG \\ ${ }^{1}$ Experimental Research Center, The First People's Hospital, Shanghai Jiaotong University, Shanghai 200080, P.R. China; \\ ${ }^{2}$ Department of Radiation Oncology, University of Colorado Health Sciences Center, Aurora, CO 80010, USA
}

Received March 13, 2013; Accepted May 2, 2013

DOI: $10.3892 /$ br.2013.115

\begin{abstract}
The expression of vascular endothelial growth factor (VEGF) is regulated by microenvironmental factors within the tumors, such as hypoxia, free radicals, $\mathrm{pH}$ imbalance and nutrient deficiency. The purpose of this study was to observe VEGF activity in tumor cells under different stress conditions. A plasmid was generated, consisting of green fluorescent protein (GFP) fused to a 1,217-bp sequence, which was located downstream and upstream of the transcriptional start site of VEGF, respectively. The plasmid was stably transfected into 4T1 mouse breast carcinoma cells. Cells were cultured in a medium with nitric oxide (NO) donor sodium nitroprusside (SNP), hypoxia-mimetic agent deferoxamine mesylate (DFX), $\mathrm{H}_{2} \mathrm{O}_{2}$, absence of serum and lowered or elevated $\mathrm{pH}$, or were heat-shocked, followed by measurement of VEGF activity by reverse transcription polymerase chain reaction (RT-PCR) and ELISA. Hypoxia, SNP and $\mathrm{H}_{2} \mathrm{O}_{2}$ led to increments of VEGF mRNA and protein expression, as well as of GFP expression. The $\mathrm{pH}$ alterations, serum deprivation and heat shock reduced VEGF mRNA expression, but had little effect on GFP expression. The results demonstrated that VEGF expression may be influenced by a number of microenvironmental factors and these factors may play important roles in regulating VEGF expression during tumorigenesis.
\end{abstract}

\section{Introduction}

The growth and metastasis of solid tumors depends on angiogenesis, the process by which new blood vessels are formed from preexisting vessels. It has been demonstrated that without adequate vasculature, tumor growth is restricted to a maximum of $2 \mathrm{~mm}$ in diameter and these nutrient and oxygen-deprived tumors may shrink or disappear (1-3). An adequate blood

Correspondence to: Professor Qian Huang, Experimental Research Center, The First People's Hospital, Shanghai Jiaotong University, 100 Haining Road, Shanghai 200080, P.R. China E-mail: qhuang@sjtu.edu.cn

Key words: vascular endothelial growth factor promoter, tumor cells, microenvironment, free radical supply suppresses the activation of signaling pathways that lead to apoptosis and prevents other forms of necrosis, thus contributing to overall tumor growth and expansion (4). Tumor angiogenesis may be initiated when the tumor consists of only $100-300$ cells or is $\sim 0.1 \mathrm{~mm}$ in diameter (5) and the density of microvessels in the tumor is closely associated with malignant potential, metastasis and recurrence (1-3). The growth and maturation of new vessels is highly dependent on vascular endothelial growth factor (VEGF) signaling, which promotes endothelial cell proliferation and migration (6). VEGF is a secreted growth factor that binds to its transmembrane receptors VEGFR-1/fms-related tyrosine kinase-1 (FLT-1) and VEGFR-2/fetal liver kinase-1(FLK-1)/KDR $(6,7)$ leading to the activation of intracellular signaling cascades and ultimately to the activation of proliferation-related genes (8). It was previously reported that VEGF expression is closely associated with the metastatic potential of breast tumors (9) and VEGF has emerged as a central target of anticancer therapies $(10,11)$.

VEGF expression in tumors is regulated in part by oxygen tension, in vivo and in vitro. Hypoxic conditions within the tumors promote VEGF transcription and increase the stability of VEGF mRNA (12). The hypoxia-induced activation of VEGF is directly regulated by the transcription factor hypoxia-inducible factor-1 (HIF-1), which binds to the hypoxia-response element (HRE) located in the 5'-flanking region of the VEGF gene $(13,14)$. In this study the question was raised whether other physiological stresses in the tumor environment, such as nutrient deficiency, $\mathrm{pH}$ imbalance, free radicals and heat, affect VEGF expression. A green fluorescent protein (GFP) reporter plasmid driven by a mouse VEGF promoter fragment was constructed and its activation in 4T1 mouse breast carcinoma cells under cellular stress conditions was monitored. Additionally, the expression of endogenous VEGF mRNA and protein was measured, as well as activation of the VEGF transactivating protein hypoxia-inducible factor $1 \alpha(\mathrm{HIF}-1 \alpha)$ in stressed 4T1 cells. We observed that nitric oxide (NO) donor sodium nitroprusside (SNP) and hydrogen peroxide positively regulated VEGF transcription levels and that VEGF expression was reduced under conditions of serum deprivation, $\mathrm{pH}$ imbalances and high temperatures. Furthermore, the non-equivalent activity of the endogenous and transgenic promoters in response to certain microenvironment perturbations suggests that VEGF contains multiple stress-responsive elements that interact in complex ways. 
Therefore, VEGF transcription and translation in carcinoma cells is affected by a wide array of cell stressors and these factors may be important determinants of VEGF expression within tumors.

\section{Materials and methods}

Isolation of VEGF promoter and construction of the reporter plasmid. The $4 \mathrm{~T} 1$ mouse breast cancer cell line was obtained from the American Type Culture Collection (ATCC; Manassas, VA, USA). The sequence from nucleotide $-1,217$ to -1 in the 5 ' non-coding region of the VEGF locus (mVP) was amplified from 4T1 genomic DNA by polymerase chain reaction (PCR) using Platinum ${ }^{\circledR}$ Taq DNA polymerase (Life Technologies, Rockville, MD, USA) and the following oligonucleotide primers (synthesized based on the published sequence at GenBank, accession number U41383) (15): 5'-ccgctcgagcgggaaccgtaagcc-3' (forward) and 5 '-cccaagcttgggaccggtaacagc-3' (reverse) in a PT-220 thermocycler (Bio-Rad, Hercules, CA, USA). The PCR conditions were $94^{\circ} \mathrm{C}$ for $5 \mathrm{~min}$, followed by 35 cycles at $94^{\circ} \mathrm{C}$ for $30 \mathrm{sec}$, $55^{\circ} \mathrm{C}$ for $1 \mathrm{~min}, 68^{\circ} \mathrm{C}$ for $2.5 \mathrm{~min}$ and $68^{\circ} \mathrm{C}$ for $7 \mathrm{~min}$. The PCR product was purified with the High Pure PCR Product Purification kit (Roche Diagnostics, Indianapolis, IN, USA) and ligated into the enhanced GFP-1 plasmid (pEGFP-1; Clontech Laboratories, Inc., Mountain View, CA, USA) with $X h o \mathrm{I}$ and HindIII restriction enzymes to yield pmVP-EGFP. Restriction enzyme analysis and DNA sequencing were applied to verify the validity of the construct.

Cell cultures and transfections. The 4T1 cells were cultured in RPMI-1640 medium ( $\mathrm{pH}$ 7.0; Life Technologies) with $10 \%$ fetal bovine serum, $100 \mathrm{U} / \mathrm{ml}$ penicillin and $100 \mathrm{~g} / \mathrm{l}$ streptomycin at $37^{\circ} \mathrm{C}$ with a constant $5 \% \mathrm{CO}_{2}$. Approximately $2 \times 10^{5}$ cells were plated on $3.5-\mathrm{cm}$ petri dishes and allowed to grow overnight to $60-70 \%$ confluence prior to being transfected with $1.5 \mu \mathrm{g}$ pmVP-VEGF plasmid DNA in $5 \mu \mathrm{l}$ Opti-MEM Reduced Serum medium (Life Technologies). The cells were trypsinized $48 \mathrm{~h}$ post-transfection and seeded in $10-\mathrm{cm}$ dishes containing standard growth medium supplemented with 200-400 $\mu \mathrm{g} / \mathrm{ml} \mathrm{G} 418$ (Life Technologies). Subsequently, resistant colonies were grown in the presence of $100 \mu \mathrm{mol} / 1$ of deferoxamine mesylate (DFX; Sigma, St. Louis, MO, USA) to induce GFP expression. After $12 \mathrm{~h}$, the cells were trypsinized for flow cytometric (FCM) analysis and the colonies with the highest GFP expression were maintained and used throughout the series.

mVEGF activity in vivo. To measure mVEGF activity in vivo, $5 \times 10^{3}$ pmVP-EGFP-expressing $4 \mathrm{~T} 1$ cells were injected subcutaneously into the ears of BALB/c mice. Under the control of the VEGF promoter, GFP expression reflected VEGF activity in tumor in vivo. Since the ears of mice are semi-transparent, the tumor cells expressing GFP were readily visualized under epifluorescent illumination. The observations were performed on days 1,5 and 8 .

In vitro microenvironment assays. PmVP-EGFP-transfected $4 \mathrm{~T} 1$ cells $\left(1 \times 10^{5}\right)$ were seeded in 24-well plates and challenged with SNP (Sigma), DFX, $\mathrm{H}_{2} \mathrm{O}_{2}$, elevated or lowered $\mathrm{pH}$, serum starvation or heat shock as follows: SNP $(0,0.5,1,1.25,1.5$, 1.75 or $2 \mathrm{mmol} / \mathrm{l}$ ) was added to the medium for $24 \mathrm{~h}$; DFX $(0,25,5075,100,125$ or $150 \mu \mathrm{mol} / \mathrm{l})$ was added for $24 \mathrm{~h} ; \mathrm{H}_{2} \mathrm{O}_{2}$ $(0,0.125,0.25,0.5$ or $1 \mathrm{mmol} / \mathrm{l})$ was added for $12 \mathrm{~h}$. Other cultures were grown in a growth medium of $\mathrm{pH} 6.3,6.8$ or 7.4 for $24 \mathrm{~h}$; a serum-deprived medium for 24 or $36 \mathrm{~h}$; or were heated to 40 or $42^{\circ} \mathrm{C}$ for 15 or $30 \mathrm{~min}$ and then returned to $37^{\circ} \mathrm{C}$ for $24 \mathrm{~h}$. After culturing, the cells were trypsinized and subjected to FCM or RT-PCR analysis, or the supernatant of the media was collected for ELISA analysis. Each treatment was repeated in duplicate.

RT-PCR and ELISA. Total RNA was extracted from cultures with TRIzol reagent (Life Technologies). Following denaturation in RNase-free water for $10 \mathrm{~min}$ at $70^{\circ} \mathrm{C}, 1 \mu \mathrm{g}$ of total RNA was reverse transcribed using the Reverse Transcription system (Promega, Madison, WI, USA) and primers with random sequences in a total volume of $20 \mu 1$. VEGF and HIF-1 $\alpha$ were then amplified from the first-strand cDNA using the following primer sets: VEGF, 5'-catcttcaagccgtcetgtgt-3' (forward) and 5'-ctccagggcttgatggttaca-3' (reverse); HIF-1 $\alpha$, 5'-gaaatggcccagtgagaaac-3' (forward) and 5'-tatcgaggctgtgtctg-3' (reverse). qPCR amplification was performed in an Opticon 2 thermal cycler (Bio-Rad) using SYBR-Green I (Takara Bio Inc., Otsu, Japan). $\beta$-actin was amplified as an internal control for each experimental condition. The level of VEGF and HIF- $1 \alpha$ mRNA relative to $\beta$-actin, $\Delta$ Ct, was determined and the fold change in expression was calculated as $2^{-\Delta \Delta C t}$. To measure the concentration of VEGF secreted from $4 \mathrm{~T} 1$ cultures, the supernatants were collected at the end of the stress period and the VEGF protein level in the media was determined using a mouse VEGF Quantikine Colorimetric Sandwich ELISA kit (R\&D Systems, Minneapolis, MN, USA). All experiments were perfomed in triplicate.

FCM. FCM was applied to measure GFP expression in pmVP-EGFP-expressing 4T1 cells. The cell colonies were dissociated with trypsin and subjected to FCM analysis to determine the mean fluorescence intensity in each experiment.

Statistical analysis. Statistical analyses were performed using SPSS software version 11.0 (SPSS, Chicago, IL, USA). Data were expressed as mean \pm standard error of the mean and analyzed by one-way ANOVA. $\mathrm{P}<0.05$ was considered to indicate a statistically significant difference.

\section{Results}

pmVP-GFP expression is induced in mouse tumors. The present study was initiated by generating a GFP reporter construct driven by a DNA fragment isolated from the upstream region of the transcriptional start site of VEGF (pmVP-GFP). The sequence from position $-1,217$ to -1 in the 5 ' non-coding region of VEGF contains binding sites known to be critical for VEGF expression, including three activator (AP)-1 sites, two AP-2 sites, a trans-acting transcription factor 1 (SP1) site, two nuclear factor- $\kappa \mathrm{B}(\mathrm{NF} \kappa \mathrm{B})$ binding sites and an HRE (15). To determine whether this fragment is sufficient to drive the GFP expression in a pattern resembling endogenous VEGF, 4T1 mouse breast carcinoma cells were stably 

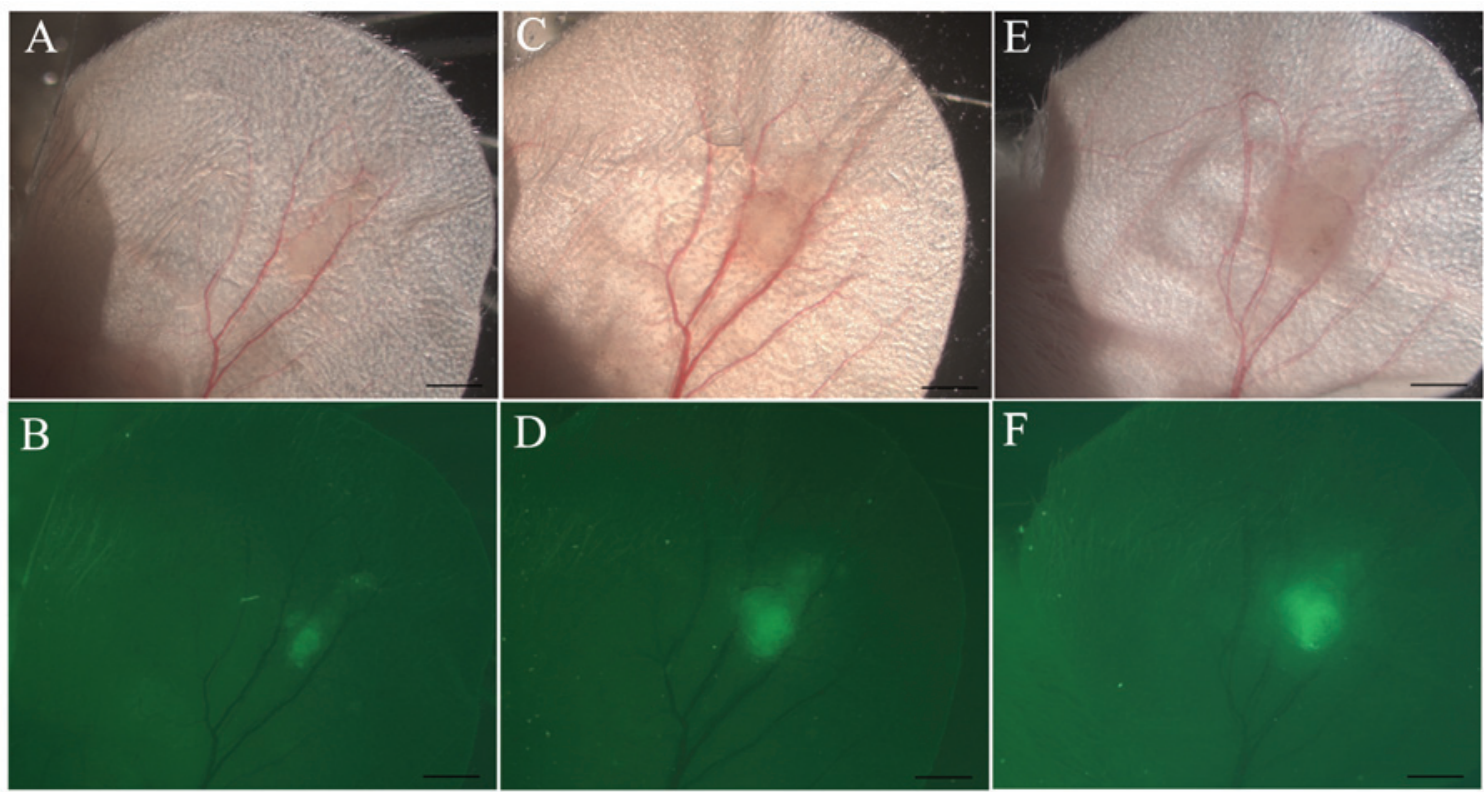

Figure 1. In vivo analysis of mVP promoter activity in tumors. Bright-field (A, C and E) and epifluorescence (B, D and F) microscopy (magnification, $\mathrm{x} 12.5$ ) revealing a pmVP-GFP 4T1 cell tumor mass on days 1 (A and B), 5 (C and D) or 8 (E and F) following subcutaneous injection of tumor cells into the ear. The contour of the tumor appears as a non-transparent area in the bright-field images. Green fluorescent protein expression is present in the tumor core. Scale bar, $500 \mu \mathrm{M}$.

transfected with pmVP-GFP and implanted subcutaneously $\left(5 \times 10^{3}\right.$ cells) into the ears of BALB/c mice (Fig. 1). Since the ears of these mice were semi-transparent, the ensuing tumor was readily visualized. After 5 days the tumor was identified as a non-transparent region $\sim 0.59 \mathrm{~mm}$ in diameter (Fig. 1C) and by day 8 the tumor had increased in size $(0.82 \mathrm{~mm}$ in diameter) and density (Fig. 1E). Under epifluorescent illumination, GFP fluorescence was observed within the core region of the tumor (Fig. 1B, D and F), demonstrating that the mVP fragment was sufficient to drive GFP expression in a pattern reminiscent of VEGF within the hypoxic core of the growing tumor mass $(4,16)$.

VEGF expression in mouse tumor cells increases in response to NO in vitro. To investigate the effect of microenvironmental stressors on VEGF expression in vitro, the cultured pmVP-EGFP-expressing 4T1 cells were exposed to NO by adding the NO donor SNP to the growth medium for $24 \mathrm{~h}$. Using mean GFP fluorescence intensity as a surrogate measure of VEGF promoter activity, we observed that increasing concentrations of SNP led to concomitant increases in the mean level of VEGF promoter activity (Fig. 2A). At its peak, GFP expression increased 0.82 \pm 0.48 -fold compared to the control levels in response to $1.75 \mathrm{mM}$ SNP. Consistent with this finding, the expression of VEGF mRNA (Fig. 2B) and VEGF protein (Fig. 2C) increased significantly in the presence of SNP $(\mathrm{P}<0.05)$. Furthermore, expression of the VEGF transcriptional regulator HIF-1 $\alpha$ was also increased when $4 \mathrm{~T} 1$ cells were exposed to SNP ( $<<0.05$, Fig. 2D). These results demonstrated that VEGF was upregulated in response to elevated concentrations of SNP, possibly in a HIF-1 $\alpha$-dependent manner. In addition, VEGF protein levels were highest in the presence of the highest concentration of SNP, whereas VEGF mRNA was mainly upregulated under lower concentrations, suggesting that independent transcrip- tional and translational mechanisms ultimately regulate the amount of VEGF protein secreted when tumor cells are exposed to SNP.

Hypoxia induces VEGF promoter activity and HIF1- $\alpha$ expression in vitro. DFX is a potent iron chelator (17) and previous studies demonstrated that the addition of DFX to growth media mimics hypoxic conditions $(18,19)$. Exposure of pmVP-EGFP-expressing 4T1 cells to DFX for $24 \mathrm{~h}$ led to a mild but significant increase in GFP ( $\mathrm{P}<0.05$, Fig. 3A), VEGF mRNA $(\mathrm{P}<0.05$, Fig. 3B) and HIF-1 $\alpha$ mRNA $(\mathrm{P}<0.05$, Fig. 3D) expression, although the changes were not overtly dose-dependent. By contrast, the VEGF protein expression was little affected by DFX (Fig. 3C).

Effects of $\mathrm{H}_{2} \mathrm{O}_{2}$, acidity, heat shock and serum starvation on $m$ VEGF promoter activity in vitro. GFP intensity and VEGF mRNA expression were investigated in pmVP-GFP-expressing 4T1 cells that were heat-shocked for 15 or $30 \mathrm{~min}$, starved for 24 or $36 \mathrm{~h}$, or cultured in media with various $\mathrm{pH}$ levels or concentrations of $\mathrm{H}_{2} \mathrm{O}_{2}$. Treating the cells with $\mathrm{H}_{2} \mathrm{O}_{2}$ induced increases in GFP and VEGF mRNA expression with little correlation between $\mathrm{H}_{2} \mathrm{O}_{2}$ concentration and the degree of change observed (Fig. 4A). However, heat shock, acidification and serum deprivation had little effect on VEGF mRNA expression (Fig. 4B).

\section{Discussion}

In this study, it was hypothesized that stresses associated with compromised blood and oxygen supply, such as nutrient deprivation, acidification and accumulation of free radicals, regulate VEGF expression. In order to investigate the effects of these microenvironmental stresses we isolated a $1.2 \mathrm{~kb}-\mathrm{DNA}$ fragment proximal to the transcriptional start site of mouse 
A

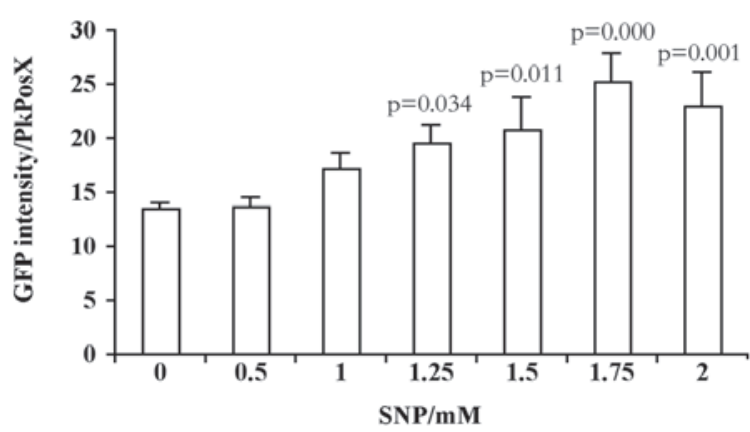

C

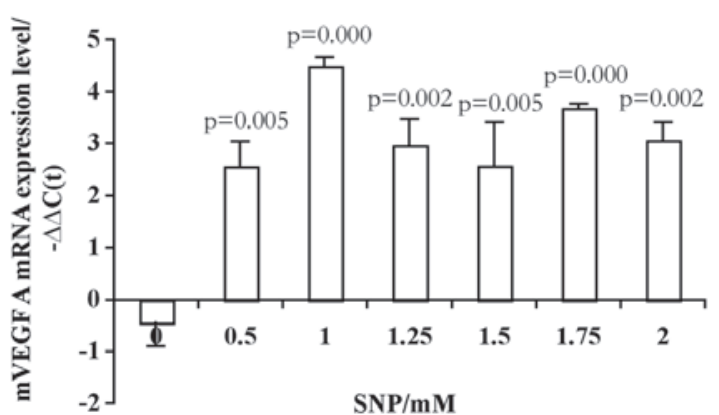

B

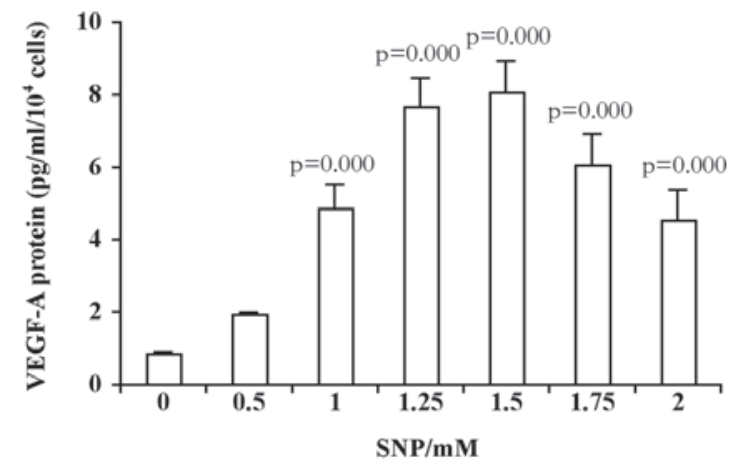

D

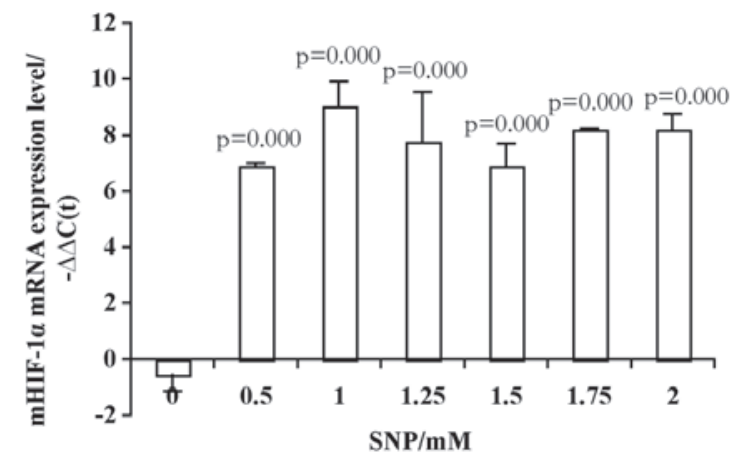

Figure 2. Vascular endothelial growth factor (VEGF) promoter activity and VEGF expression in response to nitric oxide in vitro. The values represent the mean \pm standard error of the mean normalized to the control in each treatment group. (A) Green fluorescent protein (GFP) fluorescence intensity measured by flow cytometry revealed that mVP promoter activity was increased following treatment with different concentrations of sodium nitroprusside (SNP). (B) A similar profile of responses was observed in the expression of VEGF mRNA in 4T1 cells in response to SNP. (C) The concentration of VEGF protein secreted into the growth medium increased in a dose-dependent manner in the presence of SNP. (D) Exposure of 4T1 cells to SNP significantly increased hypoxia-inducible factor $1 \alpha(\mathrm{HIF}-1 \alpha)$ mRNA expression.

A

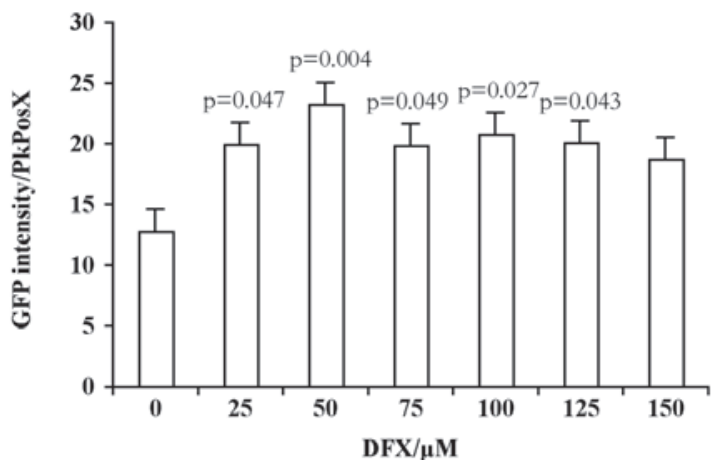

C

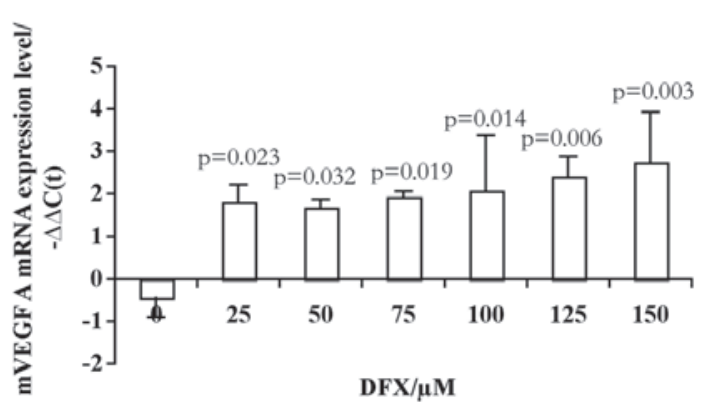

B

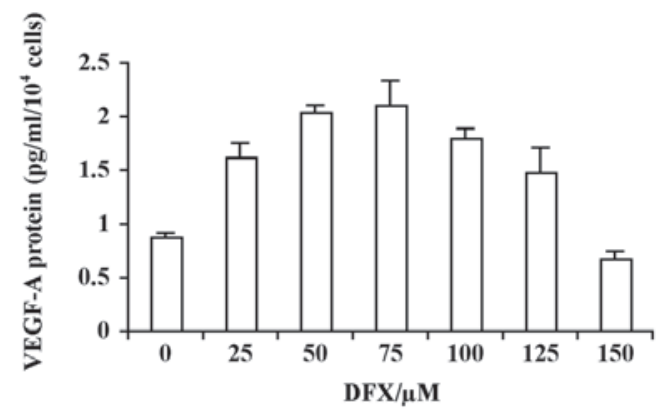

D

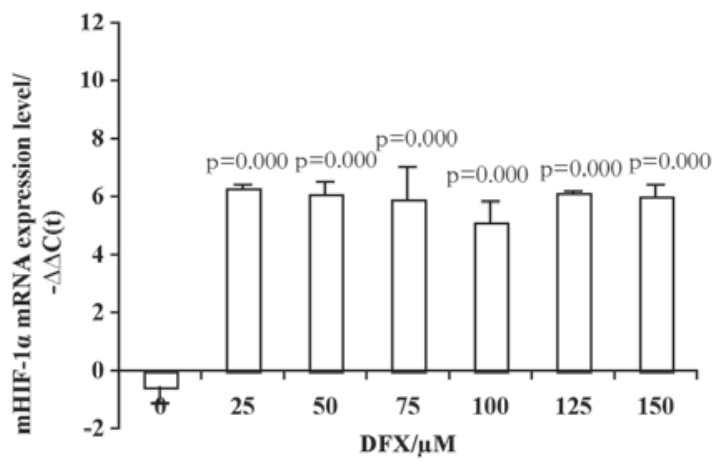

Figure 3. Vascular endothelial growth factor (VEGF) promoter activity and VEGF expression in response to hypoxia in vitro. The values show the mean \pm standard error of the mean normalized to the control in each treatment group. (A) Green fluorescent protein (GFP) fluorescence intensity measured by flow cytometry revealed that mVP promoter activity was increased following deferoxamine mesylate (DFX) treatment. (B) VEGF mRNA expression was significantly increased in response to DFX. (C) The concentration of VEGF protein secreted into the growth medium was increased in a dose-dependent manner in the presence of sodium nitroprusside (SNP) but was not affected by DFX. (D) Exposure of 4T1 cells to SNP significantly increased hypoxia-inducible factor $1 \alpha(\mathrm{HIF}-1 \alpha)$ mRNA expression, whereas DFX caused only minor changes in HIF-1 $\alpha$ expression. 
A

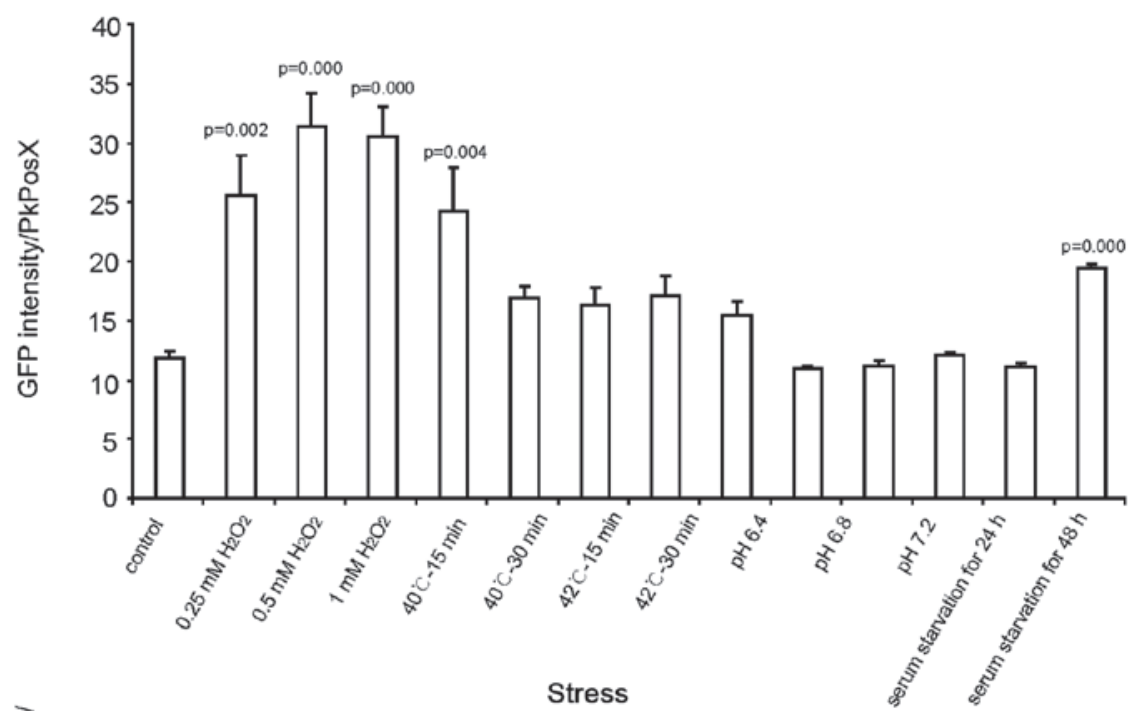

B

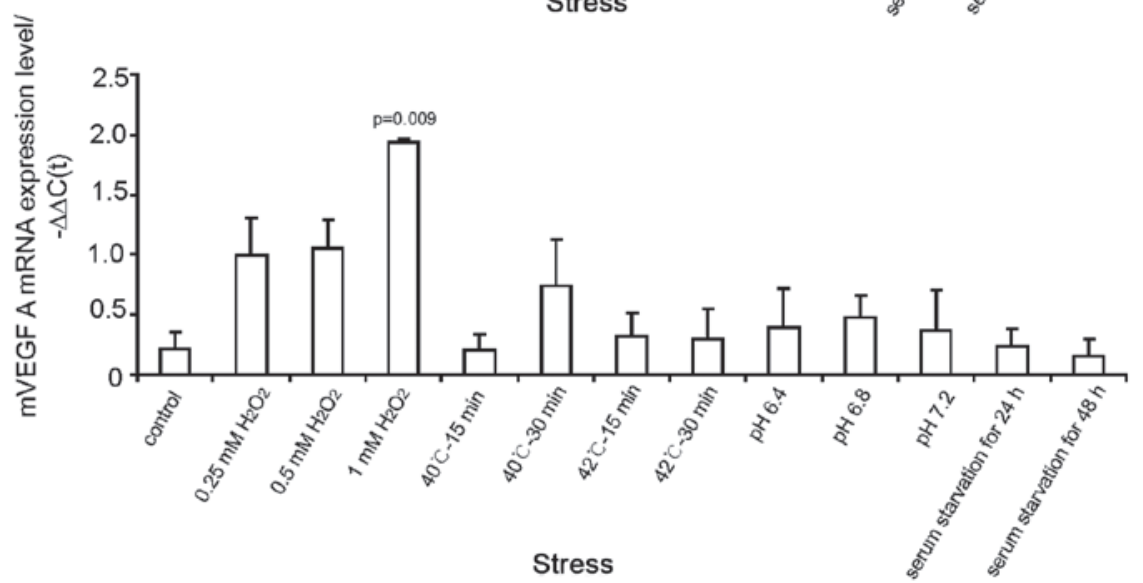

Figure 4. Vascular endothelial growth factor (VEGF) promoter activity and VEGF expression under conditions of cellular stress such as $\mathrm{H}_{2} \mathrm{O}_{2}$, heat, $\mathrm{pH}$ imbalance and serum deprivation. The values represent the mean \pm standard error of the mean normalized to the control in each treatment group. (A) Green fluorescent protein (GFP) fluorescence intensity measured by flow cytometry revealed that $\mathrm{mVP}$ promoter activity was increased following treatment with $\mathrm{H}_{2} \mathrm{O}_{2}$ and long-term serum starvation but was not affected by temperature changes. Lowering or elevating the $\mathrm{pH}$ of the growth medium led to minor changes in GFP expression. (B) An elevated level of VEGF mRNA expression was observed in response to $\mathrm{H}_{2} \mathrm{O}_{2}$; however, heating, pH changes and serum starvation led to minor changes.

VEGF and fused it with GFP. This fragment possesses three activator AP-1 sites, two AP-2 sites, one trans-acting transcription factor 1 (SP1) site, two NFкB binding sites, one HRE and likely several other consensus sequences. This fragment mediated an upregulation of GFP in cultured 4T1 cells grown under low oxygen conditions (Figs. 2A, 3A and $4 \mathrm{~A}$ ) and in vivo within the core of pmVP-GFP-expressing 4T1-cell tumors (Fig. 1). These responses were similar to the dynamic changes in endogenous VEGF expression in tumors (16) and cells otherwise grown under hypoxic conditions (Fig. 3) (21), suggesting that regulatory elements within the fragment are sufficient to promote hypoxia-induced VEGF transcription (20).

VEGF and $\mathrm{mVP}$ promoter activities were increased in the cultured 4T1 cells in the presence of $\mathrm{H}_{2} \mathrm{O}_{2}$ and high concentrations of the NO donor SNP. These findings are consistent with those of a previous study on VEGF expression in ovarian cancers (21) and suggest that free radical levels in the tumor microenvironment regulate VEGF expression. High levels of SNP also increased the level of VEGF protein, demonstrating that free radical loading directly affects the amount of VEGF secreted from the 4T1 carcinoma cells. However, exposure to the oxygen chelator DFX had little effect on the level of VEGF protein, a finding that was not consistent with what was observed in brain tumors $(12,16)$. This inconsistency may reflect differences among cell lines. For example, in the 4T1 cells but not in other cell lines, hypoxia may decrease the stability of VEGF protein, whereas high levels of free radicals may increase protein stability. However, this possibility requires further investigation.

Heat shock, $\mathrm{pH}$ level alterations and serum deprivation had little effect on VEGF mRNA expression and mVP-driven GFP expression in cultured 4T1 cells. These differential responses suggest that there are enhancer elements outside the $\mathrm{mVP}$ sequence that interact with $\mathrm{pH}$ and nutrient response elements within the mVP fragment. For example, our findings suggest that the proximal 5 ' region contains an element (or elements) that supports the upregulation of VEGF in periods of starvation. However, this activity is usually inhibited by interactions with other elements located further upstream or downstream of the coding region. Consistent with this possibility, a previous study demonstrated that a complex containing transcription factor ATF4 binds to an element located 1,767 bp downstream of the VEGF coding sequence and that ATF4 activity regulates 
the expression of VEGF expression in response to oxidative stress in a HIF-1-independent manner (22). Findings of that study support our conclusion that the VEGF locus contains binding sites outside the proximal 5' non-coding region that regulate VEGF expression in cells exposed to different microenvironmental stressors. The identification of physiological and genetic factors that affect VEGF transcriptional regulation in tumor cells, as well as understanding the organization of the VEGF regulatory regions may be critical for the design of treatment strategies aiming at mitigating VEGF expression during tumor growth and metastasis $(20,23)$.

\section{Acknowledgements}

We would like to thank the entire staff at the experimental center of The First People's Hospital for their assistance. This study was supported by grants from the National Basic Research Program of China (973 project, 2004CB518804), the National Natural Science Foundation of China (30325043), the Project for Talent Accomplishment of the Health Bureau of Shanghai, China (99BR006), the Shanghai Rising-Star Program, China (04QMX1417), the Foundation of Young Scientists of the Health Bureau of Shanghai, China (131014Y3) and the Shanghai Natural Science Foundation, China (11ZR1429400).

\section{References}

1. Carmeliet P and Jain RK: Angiogenesis in cancer and other diseases. Nature 407: 249-257, 2000.

2. Folkman J: Tumor angiogenesis. Adv Cancer Res 43: 175-203, 1985.

3. Folkman J, Watson K, Ingber D and Hanahan D: Induction of angiogenesis during the transition from hyperplasia to neoplasia. Nature 339: 58-61, 1989.

4. Bellen JA, Van Diest PJ and Baak JP: Relationships between vascularization and proliferation in invasive breast cancer. J Pathol 189: 309-318, 1999.

5. Li CY, Shan S, Huang Q, Braun RD, Lanzen J, Hu K, Lin P and Dewhirst MW: Initial stages of tumor cell-induced angiogenesis: evaluation via skin window chambers in rodent models. J Natl Cancer Inst 92: 143-147, 2000.

6. de Vries C, Escobedo JA, Ueno H, Houck K, Ferrara N and William LT: The fms-like tyrosine kinase, a receptor for vascular endothelial growth factor. Science 255: 989-991, 1992.

7. Millauer B, Wizigmann-Voos S, Schnurch H, Martinez R, Møller NP, Risau W and Ullrich A: High affinity VEGF binding and developmental expression suggest Flk-1 as a major regulator of vasculogenesis and angiogenesis. Cell 72: 835-846, 1993.

8. Mazure NM, Chen EY, Laderoute KR and Giaccia AJ: Induction of vascular endothelial growth factor by hypoxia is modulated by a phosphatidylinositol 3-kinase/Akt signaling pathway in Ha-ras-transformed cells through a hypoxia inducible factor-1 transcriptional element. Blood 90: 3322-3331, 1997.

9. Bolat F, Kayaselcuk F, Nursal TZ, Yagmurdur MC, Bal N and Demirhan B: Microvessel density, VEGF expression, and tumor-associated macrophages in breast tumors: correlations with prognostic parameters. J Exp Clin Cancer Res 25: 365-372, 2006.
10. Holash J, Maisonpierre PC, Compton D, Boland P, Alexander CR, Zagzag D, Yancopoulos GD and Wiegand SJ: Vessel cooption, regression, and growth in tumors mediated by angiopoietins and VEGF. Science 284: 1994-1998, 1999.

11. Yancopoulos GD, Davis S, Gale NW, Rudge JS, Wiegand SJ and Holash J: Vascular-specific growth factors and blood vessel formation. Nature 407: 242-248, 2000.

12. Ikeda E, Achen MG, Breier G and Risau W: Hypoxia-induced transcriptional activation and increased mRNA stability of vascular endothelial growth factor in C6 glioma cells. J Biol Chem 270: 19761-19766, 1995.

13. Forsythe JA, Jiang BH, Iyer NV, Agani F, Leung SW, Koos RD and Semenza GL: Activation of vascular endothelial growth factor gene transcription by hypoxia-inducible factor 1 . Mol Cell Biol 16: 4604-4613, 1996.

14. Levy NS, Goldberg MA and Levy AP: Sequencing of the human vascular endothelial growth factor (VEGF) 3' untranslated region (UTR): conservation of five hypoxia-inducible RNA-protein binding sites. Biochem Biophys Acta 1352: 167-173, 1997.

15. Shima DT, Kuroki M, Deutsch U, Ng YS, Adamis AP and D'Amore PA: The mouse gene for vascular endothelial growth factor. Genomic structure, definition of the transcriptional unit, and characterization of transcriptional and post-transcriptional regulatory sequences. J Biol Chem 271: 3877-3883, 1996.

16. Fukumura D, Xu L, Chen Y, Gohongi T, Seed B and Jain RK: Hypoxia and acidosis independently up-regulate vascular endothelial growth factor transcription in brain tumors in vivo. Cancer Res 61: 6020-6024, 2001.

17. Melillo G, Taylor LS, Brooks A, Musso T, Cox GW and Varesio L: Functional requirement of the hypoxia-responsive element in the activation of the inducible nitric oxide synthase promoter by the iron chelator desferrioxamine. J Biol Chem 272: 12236-12243, 1997.

18. Wang GL and Semenza GL: Desferrioxamine induces erythropoietin gene expression and hypoxia-inducible factor 1 DNA-binding activity: implications for models of hypoxia signal transduction. Blood 82: 3610-3615, 1993.

19. Potier E, Ferreira E, Dennler S, Mauviel A, Oudina K, Logeart-Avramoglou D and Petite H: Desferrioxamine-driven upregulation of angiogenic factor expression by human bone marrow stromal cells. J Tissue Eng Regen Med 2: 272-278, 2008.

20. Koshikawa N, Takenaga K, Tagawa M and Sakiyama S: Therapeutic efficacy of the suicide gene driven by the promoter of vascular endothelial growth factor gene against hypoxic tumor cells. Cancer Res 60: 2936-2941, 2000.

21. Liu LZ, Hu XW, Xia C, He J, Zhou Q, Shi X, Fang J and Jiang BH: Reactive oxygen species regulate epidermal growth factor-induced vascular endothelial growth factor and hypoxia-inducible factor- $1 \alpha$ expression through activation of AKT and P70S6K1 in human ovarian cancer cells. Free Radic Biol Med 41: 1521-1533, 2006.

22. Roybal CN, Hunsaker LA, Barbash O, Vander Jagt DL and Abcouwer SF: The oxidative stressor arsenite activates vascular endothelial growth factor mRNA transcription by an ATF4-dependent mechanism. J Biol Chem 280: 20331-20339, 2005.

23. Jung YD, Nakano K, Liu W, Gallick GE and Ellis LM: Extracellular signal-regulated kinase activation is required for up-regulation of vascular endothelial growth factor by serum starvation in human colon carcinoma cells. Cancer Res 59: 4804-4807, 1999. 